\title{
Sosialisasi Dan Pelatihan Pembuatan Bangunan Rumah Tahan Gempa Di Desa Pemenang Timur Kabupaten Lombok Utara
}

\author{
Buan Anshari, Ni Nyoman Kencanawati, Jauhar Fajrin, Hartana, Agus Suroso
}

Progam Studi Teknik Sipil, Universitas Mataram, Indonesia

\begin{abstract}
Kata Kunci: rumah tahan gempa, kecamatan pemenang timur, kabupaten lombok utara

Abstrak: Provinsi Nusa Tenggara Barat (NTB), yang terdiri dari Pulau Lombok dan Sumbawa, berada pada posisi yang dekat dengan pertemuan dua lempeng yaitu Lempeng Indo-Australia di bagian selatan dan Lempeng Eurasia di bagian utara. Pada tempat pertemuan lempeng tersebut, yang dikenal dengan nama zona subduksi, terjadi tumbukan/pergesekan yang dapat menjadi sumber terjadinya letusan gunung api, gempa bumi dan tsunami. Pada Tahun 2018, bencana gempa bumipun terjadi yang berpusat pada Kecamatan Kayangan Kabupaten Lombok Utara. Menurut laporan BNPB (2018), bencana gempa bumi tersebut memakan korban jiwa, baik meninggal maupun luka luka. Pada daerah terdampak tersebut, diperlukan pengetahuan tentang bagaimana cara merencanakan suatu bangunan yang aman terhadap bahaya gempa. Dalam hal ini akan disampaikan panduan teknis langkah-langkah merencanakan, mendesain dan melaksanakan suatu bangunan yang aman terhadap gempa bumi. Disamping itu akan diberikan pemahaman bagaiman cara memperbaiki rumah tembok yang mengalami kerusakan ringan sampai sedang agar bisa berfungsi sebagai rumah yang aman terhadap gempa mengacu ke juknis dari Kementerian PU, Dirjen Cipta Karya (2006).
\end{abstract}

\section{Korespondensi: buan.anshari@unram.ac.id}

\section{PENDAHULUAN}

Kepulauan Indonesia merupakan wilayah yang rawan terjadi bencana geologi khususnya gempa bumi dan tsunami karena terletak pada pertemuan tiga lempeng dunia yaitu lempeng Eurasia, lempeng Indo-Australia dan lempeng Samudera Pasifik. Provinsi Nusa Tenggara Barat (NTB), yang terdiri dari Pulau Lombok dan Sumbawa, berada pada posisi yang dekat dengan pertemuan dua lempeng tersebut yaitu Lempeng Indo-Australia di bagian selatan dan Lempeng Eurasia di bagian utara. Pada tempat pertemuan lempeng tersebut, yang dikenal dengan nama zona subduksi, terjadi tumbukan/pergesekan yang dapat menjadi sumber terjadinya letusan gunung api, gempa bumi dan tsunami. Sejarah bencana gempa bumi di Indonesia mengindikasikan terdapat banyaknya bangunan termasuk sekolah dan rumah tinggal yang rusak maupun hancur. Peristiwa terakhir gempa bumi di Lombok, Nusa Tenggara Barat dan Palu Sulawesi Tengah akhir 2018 telah menghancurkan sebagian besar bangunan di daerah berdampak bencana tersebut.

Menurut BMKG(2018), sejak akhir bulan Juli 2018 hingga akhir bulan Agustus 2018 wilayah kepulauan Nusa Tenggara, khususnya Pulau Lombok dan Sumbawa, mengalami gempa bumi beruntun yang cukup besar. Berdasarkan siaran Pers Badan Meteorologi, Klimatologi dan Geofisika (BMKG) Indonesia, gempa pertama terjadi pada hari Minggu tanggal 29 Juli 2018 jam 06:47:39 WITA dengan kekuatan $M=6.4$ Skala Richter (SR) dan lokasi di darat bagian timur laut Pulau Lombok. Akibat gempa pertama ini hanya wilayah 
Kabupaten Lombok Timur bagian utara (Sembalun, Sambelia) dan sebagian kecil wilayah Kabupaten Lombok Utara bagian timur (Kayangan, Bayan) yang mengalami kerusakan parah. Selang tujuh hari berikutnya tepatnya pada hari Minggu tanggal 5 Agustus 2018 jam 19:46:35 WITA terjadi gempa bumi kedua dengan kekuatan $\mathrm{M}=7.0$ SR dan lokasi juga di darat bagian timur laut Pulau Lombok. Kerusakan akibat gempa kedua ini meluas hampir di seluruh wilayah Kabupaten Lombok Utara, ditambah wilayah Kabupaten Lombok Barat bagian utara dan sebagian kecil wilayah Kota Mataram. Gempa kedua ini juga disertai peringatan kemungkinan adanya gelombang tsunami dengan tingkat Waspada (perkiraan tinggi gelombang $0.5 \mathrm{~m}$ ) yang menimbulkan kepanikan masyarakat khususnya di wilayah Kota Mataram. Gempa ketiga terjadi pada hari Kamis tanggal 9 Agustus 2018 jam 13:25:32 WITA dengan kekuatan $\mathrm{M}=5.9$ SR dan lokasi di darat bagian barat laut Pulau Lombok. Gempa keempat terjadi pada hari Minggu tanggal 19 Agustus 2018 jam 22:56:27 WITA dengan kekuatan $\mathrm{M}=6.9 \mathrm{SR}$ dan lokasi di darat bagian ujung timur laut Pulau Lombok. Gempa keempat ini menyebabkan wilayah yang terdampak meluas hingga Kabupaten Sumbawa bagian barat (Alas) dan sebagian kecil Kabupaten Sumbawa Barat (Seteluk).

Menurut laporan BNPB (2018), jumlah korban jiwa meninggal dunia selama Gempa Lombok 2018 total sebanyak 564 orang dengan rincian, yaitu Kabupaten Lombok Utara sebanyak 467 orang, Kabupaten Lombok Barat sebanyak 44 orang, dan Kabupaten Lombok Timur sebanyak 31 orang, Selain itu, sebanyak 2 korban berada di Kabupaten Lombok Tengah, 9 korban berada di Kota Mataram, 6 orang di Kabupaten Sumbawa, dan 5 korban di Kabupaten Sumbawa Barat. Untuk korban luka dilaporkan ada 1.584 korban luka-luka yang tersebar di beberapa tempat. Daerah dengan korban luka-luka terbanyak berada di Lombok Utara dengan jumlah 829 orang. Sementara, Lombok Barat sebanyak 399 orang dan Lombok Timur sebanyak 122 orang. Kemudian, korban luka-luka di Sumbawa Barat berjumlah 115 orang.

Mengingat banyaknya korban jiwa dan bangunan rumah yang rusak atau hancur maka di daerah yang berdampak sebagai lokasi mitra perlu diberikan pengetahuan tentang bagaimana cara merencanakan suatu bangunan yang aman terhadap bahaya gempa. Dalam hal ini akan disampaikan panduan teknis langkah-langkah merencanakan, mendesain dan melaksanakan suatu bangunan yang aman terhadap gempa bumi. Disamping itu akan diberikan pemahaman bagaiman cara memperbaiki rumah tembok yang mengalami kerusakan ringan sampai sedang agar bisa berfungsi sebagai rumah yang aman terhadap gempa mengacu ke juknis dari Kementerian PU, Dirjen Cipta Karya (2006).

Melihat tingkat kerusakan infrastruktur yang dialami oleh daerah Lombok Utara khususnya desa Pemenang Timur maka hampir dapat dipastikan bahwa selama ini warga setempat dalam membangun rumah sering mengabaikan kaidah kaidah rumah tahan gempa seperti disampaikan oleh Boen (2009) yaitu:

1. Kualitas material (beton, mortar, batu fondasi, dan kayu) konstruksi yang baik,

2. Keberadaan dan dimensi struktur (fondasi, balok pengikat, kolom, balok keliling, atap, dan dinding) yang sesuai,

3. Seluruh elemen struktur utama tersambung dengan baik, dan

4. Mutu pengerjaan yang baik 
Oleh karena itu masyarakat setempat sebagai mitra kegiatan ini perlu diberi bekal ilmu untuk memberikan pemahaman tentang cara membangun rumah yang aman terhadap gempa dan cara perbaikan rumah yang mengalami kerusakan akibat gempa bumi. Dalam kegiatan ini dengan melibatkan mahasiswa KKN Tematik Universitas Mataram akan memberikan penyuluhan dan demonstrasi tentang pembangunan baru dan perbaikan rumah tembokan yang aman terhadap bahaya gempa bumi.

Target yang ingin dicapai adalah meningkatkan pemahaman dan ketrampilan warga setempat tentang prinsip prinsip dasar dalam membangun rumah yang aman terhadap kejadian gempa bumi.

\section{METODE PELAKSANAAN}

Metode kegiatan dilakukan dengan metode ceramah pada awalnya dan dilanjutkan dengan praktek pembuatan tembokan dengan kolom beton yang aman terhadap bahaya gempa. Rangkaian kegiatan yang telah dilaksanakan adalah sebagai berikut:

a. Pengenalan tentang kejadian bencana alam seperti gempa dan bencana alam lainnya

b. Memaparkan dengan LCD projector tentang pentingnya pembangunan rumah yang aman terhadap bahaya gempa.

c. Menjelaskan tata cara membangun rumah sederhana system tembokan

d. Mempraktekkan cara merangkai besi tulang balok/kolom yang memenuhi kaidah tahan gempa

e. Mempraktekkan cara mengikat tembok bata dengan balok/kolom dengan penjangkaran angker/stek

f. Memperkenalkan cara perbaikan atau perkuatan tembok yang mengalami kerusakan akibat gempa.

g. Memutar video tentang cara perbaikan bangunan yang mengalami kerusakan akibat gempa bumi.

h. Diskusi dan tanya jawab dengan peserta yang sebagian besar berprofesi sebagai tukang atau buruh bangunan.

Sebelum dilaksanakan penyuluhan, maka dilakukan koordinasi terlebih dahulu dengan pihak Pemerintah Desa Pemenang Timur. Desa Pemenang Timur merupakan salah satu desa dari empat desa yang ada di Kecamatan Pemenang yang berjarak $\pm 1 \mathrm{~km}$ dari pusat Kecamatan Pemenang dan $\pm 9 \mathrm{~km}$ dari pusat Pemerintahan Kabupaten Lombok Utara. Satu minggu sebelum acara penyuluhan dilaksanakan, tim pelaksana turun ke desa untuk mempersiapkan detail pelaksanaan kegiatan, menyampaikan undangan untuk peserta dan halhal teknis terkait dengan pelaksanaan kegiatan. Lokasi kegiatan penyuluhan dilaksanakan di Gedung Sementara SD di Desa Pemenang Timur. Peta Lokasi Desa bisa dilihat pada Gambar 1. Secara geografis Desa Pemenang Timur batas-batasnya adalah sebagai berikut:

a. Sebelah Utara berbatasan dengan Desa Gili Indah, Pemenang

b. Sebelah Selatan berbatasan dengan Desa Lembah Sari, Kec. Batlayar

c. Sebelah Barat berbatasan dengan Desa Pemenang Barat, Pemenang

d. Sebelah Timur berbatasan dengan Desa Sigar Penjalin, Kec. Tanjung 


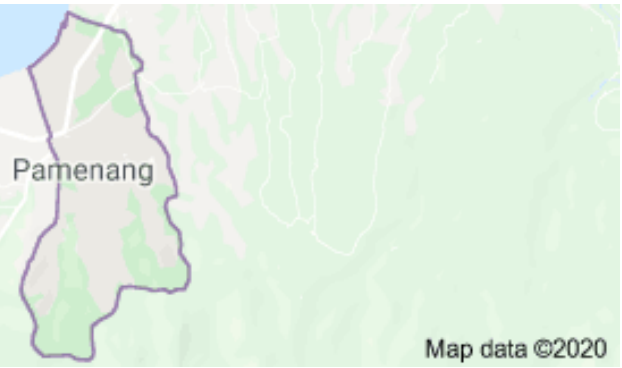

Gambar 1. Peta Desa Pemenang Timu, Kecamatan Pemenang, KLU

Desa Pemenang Timur tergolong daerah beriklim tropis dengan temperature rata-rata $30^{\circ} \mathrm{C}$, sedangkan curah hujan rata-rata 1758 MM pertahun dengan jumlah hujan 6 bulan setiap tahun.secara geografis Desa Pemenang Timur terletak di $110^{\circ} 48^{\prime} 55,12^{\prime \prime}$ BT dan terletak di $7^{\circ} 02^{\prime} 27,52^{\prime \prime} L S$. Secara topografi Desa Pemenang Timur termasuk dalam kategori wilayah dataran, perbukitan dan dataran rendah dengan ketinggian \pm 50 meter dari permukaan laut (MDPL).

\section{HASIL DAN PEMBAHASAN}

Kegiatan penyuluhan dilaksanakan pada bulan Agustus 2019 dengan melibatkan 30 orang peserta. Peserta tersebut merupakan perwakilan dari masing-masing dusun yang ada di wilayah desa Pemenang Timur. Latar belakang peserta adalah warga desa yang berprofesi sebagai tukang atau pekerja bangunan serta perangakat desa seperti para Kepala Dusun maupun warga masyarakat umum yang berminat mengikuti acara ini. Kegiatan diawali dengan pembukaan yang diisi dengan sambutan dari pihak desa diwakili Sekretaris Desa Pemenang Timur dan Tim Pelaksana Magister Teknik Sipil Unram. Selanjutnya pemaparan materi dan diskusi. Dilanjutkan dengan pelatihan atau praktek pembuatan tulangan balok atau kolom dipandu oleh Tim Pelaksana dari Magister Teknik Sipil Unram. Selanjutnya acara ditutup dan peserta menikmati snack yang disediakan panitia. Beberapa dokumentasi kegiatan pengabdian dapat dilihat pada Gambar 2(a)-(d).

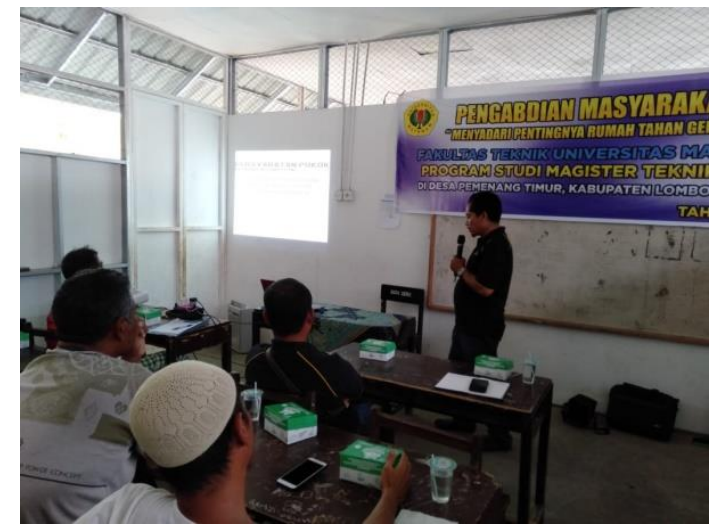

(a)

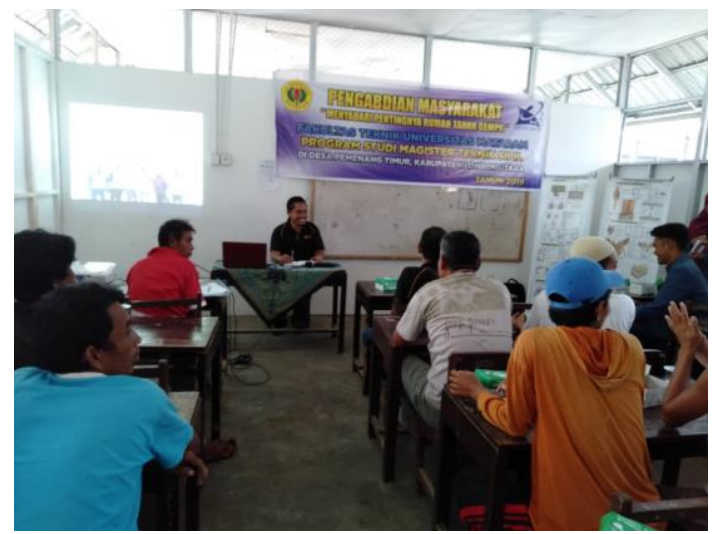

(b) 


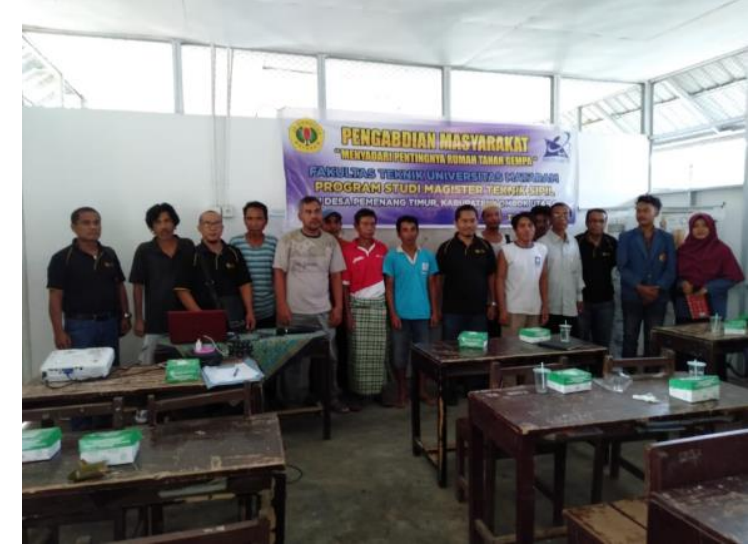

(c)

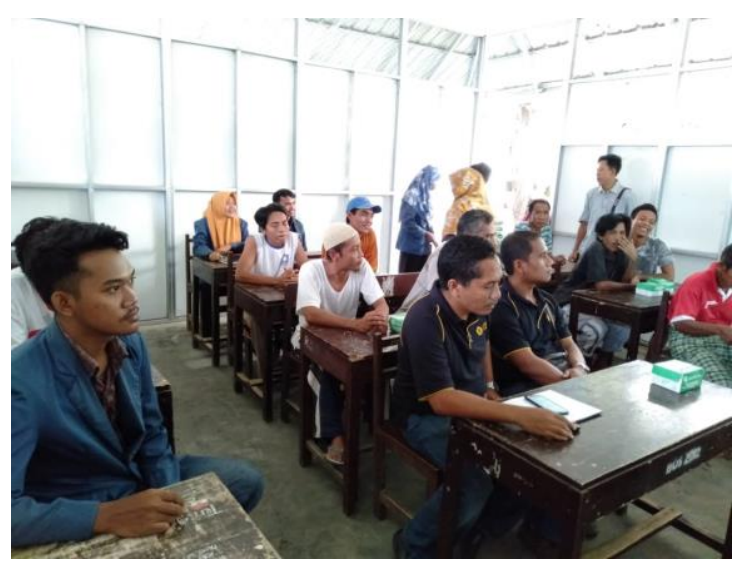

(d)

Gambar 2. Beberapa foto kegiatan Pengabdian Masyarakat di Desa Pemenang Timur

\section{KESIMPULAN DAN SARAN}

Berdasarkan hasil pelaksanaan kegiatan pengabdian kepada masyarakat ini tentang Sosialisasi dan Pelatihan Pembuatan Bangunan Rumah Tahan Gempa Di Desa Pemenang Timur Kabupaten Lombok Utara maka dapat diambil kesimpulan sebagai berikut:

1. Pelaksanaan kegiatan penyuluhan secara umum berjalan dengan baik dan lancar sesuai harapan.

2. Peserta mendapatkan informasi tentang bahaya bangunan yang tidak dibangun mengikuti kaidah tahan gempa dalam pelaksanaannya.

3. Materi yang disampaikan mampu menarik minat peserta untuk terlibat aktif dalam diskusi karena disampaikan audio, visual dan praktek.

4. Peserta sangat bersemangat untuk mempraktekkan cara merangkai tulangan atau besi untuk balok dan kolom yang memenuhi syarat banguan tahan gempa.

\section{DAFTAR PUSTAKA}

Dirjen Cipta Karya, 2006, Pedoman Teknis Rumah dan Bangunan Gedung Tahan Gempa dilengkapi dengan Metode dan Cara Perbaikan Kerusakan, Departmen PU, Jakarta

Teddy Boen, 2009, Membangun Rumah Tembokan Tahan Gempa, Jakarta

BMKG, 2018, Laporan Survei Gempa Merusak M : 7.0 di Lombok 5 Agustus 2018, BMKG Mataram NTB

BNPB, 2018, Press release Badan Nasinal Penanganan Bencana tentang Bencana Gempa Lombok 2018, Jakarta 